\title{
Dietary habits, obesity and university life for nurse undergraduates ${ }^{1}$
}

\section{Hábitos dietéticos, obesidad y vida universitaria para estudiantes de enfermería}

\author{
Dimitrios Theofanidis* \\ dimitrisnoni@yahoo.gr
}

Antigoni Fountouki ${ }^{* *}$

antifountou@yahoo.gr

\begin{abstract}
Health behavior of nursing students is often inadequate in terms of dietary, physical activity, smoking and alcohol drinking habits. The main aim of this position paper is to explore dietary habits, obesity and university life on nurse undergraduates. This critical review covers three distinct dimensions of student life as related to nursing studies, i.e. the eating and lifestyle behaviors of nursing students; the transitional period and risk of gain weight;

students' national origin and eating behaviors.

Obesity is increasing not only in the western world but in developing countries as well. University life is a transitional period where risk of weight gain is increased. Often, stress may lead students to 'binge' eating and weight problems. In terms of students' national origin and eating behavior, dietary choices for nurse students are multifaceted, as their cultural
\end{abstract}

Financial Disclosure: The authors would like to clarify that there is no financial interest associated with this review article.

- BSc, MSc, PhD, Assistant Professor, Nursing Department, ATEI, Greece.

* Sc, MSc, Clinical Lecturer, Nursing Department, ATEl, Greece.

Received April 20, 2018 / Accepted May 30, 2018. 


\section{Theofanidis Dimitrios, Fountouki Antigoni}

backgrounds may be. Nurses, amongst other healthcare professionals, encounter barriers to positive lifestyles and healthy eating just as many of their patients do. Moreover, as healthcare professionals are regarded as potential health promoters, their own health behavior represents an important key clinical and educational function.

Yet, nutritional knowledge is not easy to apply as there is so much misinformation readily available both online and elsewhere.

Given the highly stressful conditions associated with their profession, nurses also need to care for their own health. Thus there is a need for designing educational programs for current nursing curricula to encourage healthy lifestyles which include coping with stress, increased physical activity, healthy food and drink choices.

Keywords: diet habits, nursing students, nutrition

\section{Resumen}

El comportamiento de salud de los estudiantes de enfermería a menudo es inadecuado en términos de hábitos alimenticios, actividad física, tabaquismo y consumo de alcohol. El objetivo principal de este documento de posición es explorar los hábitos alimentarios, la obesidad y la vida universitaria en estudiantes de enfermería. Esta revisión crítica cubre tres dimensiones distintas de la vida estudiantil relacionadas con los estudios de enfermería, es decir, las conductas de alimentación y estilo de vida de los estudiantes de enfermería; el período de transición y el riesgo de ganar peso; el origen nacional de los estudiantes y las conductas alimentarias.

La obesidad está aumentando no solo en el mundo occidental, sino también en los países en desarrollo. La vida universitaria es un período de transición donde aumenta el riesgo de aumento de peso. A menudo, el estrés puede llevar a los estudiantes a "atracones" de problemas de alimentación y peso. En términos de origen

76 Instituto de Investigación y Evaluación Educativas y Sociales / Universidad Pedagógica Nacional Francisco Morazán

(7) Los artículos de la Revista Electrónica Paradigma del Instituto de Investigación y Evaluación Educativas y Sociales de la Universidad Pedagógica Nacional Francisco Morazán, se comparten bajo términos de la Licencia Creative Commons: Se permite que otros puedan escargar las obras y compartirlas con otras personas, siempre y cuando se reconozca su autoría, pero no se pueden cambiar de BY NC ND descargar las obras y compatillas lon otras peranas, sem 
nacional y comportamiento alimentario de los estudiantes, las elecciones dietéticas para las estudiantes de enfermería son multifacéticas, como pueden ser sus antecedentes culturales. Las enfermeras, entre otros profesionales de la salud, encuentran barreras para estilos de vida positivos y una alimentación saludable, al igual que muchos de sus pacientes. Además, como los profesionales de la salud son considerados como posibles promotores de salud, su propio comportamiento de salud representa una importante función clínica y educativa. Sin embargo, el conocimiento nutricional no es fácil de aplicar ya que hay mucha desinformación disponible tanto en línea como en otros lugares.

Dadas las condiciones altamente estresantes asociadas con su profesión, las enfermeras también deben cuidar su propia salud. Por lo tanto, existe la necesidad de diseñar programas educativos para los currículos de enfermería actuales para alentar estilos de vida saludables que incluyen lidiar con el estrés, el aumento de la actividad física, alimentos saludables y opciones de bebidas.

Palabras clave: hábitos alimentarios, estudiantes de enfermería, nutrición

\section{Introduction}

Given the steady rise of chronic disease rates globally, nurses, as part of a multidisciplinary team, often find themselves at the forefront of providing specific nutrition education as part of routine clinical patient care. Thus, nutritional knowledge is becoming more essential as part of nursing curricula and should be taught either as a standalone course or integrated into multiple advanced courses. Yet, many nurses have been raising concerns about their inadequate training to confront their role in providing sound nutritional advice to patients (Ismawati et al., 2014).

Although elements of the promotion of healthy dietary and lifestyle choices is included in some nursing curricula worldwide, still, several studies of nursing students have uncovered a high prevalence of 
unhealthy behaviors (Kolleck, 2004; Purcell et al., 2006). Nursing students at university are a particular target population that should be extensively informed concerning health issues and ways to teach and encourage healthier lifestyle practices. Sadly though, it seems that this group has moved away from traditional dietary practices and this is of concern as it hampers their role in health promotion which, if followed, may lead to many positive health outcomes (Evagelou et al., 2014).

Yet, even after graduation, poor habits may follow well into the professional lives of many nurses. In this light, studies have shown that health care professionals, especially nurses, tend to underestimate their BMI and health/associated risks associated with being overweight or obese; the latter is a multi-factorial condition and arises from a combination of inappropriate diet, lack of physical activity, sleep deprivation and increased stress from work, among other factors (Vandelanotte et al., 2011; Knutson, 2012).

With rates of obesity on the rise globally, nurses should be more involved in the lifestyle management of patients, and to recognize the barriers that inhibit them discussing effective weight management strategies with patients. In these lines, obesity management is a role that nursing students will need to be equipped with and more likely to be targeted for future training developments in tackling the global increase in rates of obesity. A study in the UK found that nurse students perceived obesity management as essential to their training, but still, they reportedly lacked the confidence and techniques to discuss this with their patients (Keyworth et al., 2013). Thus, the lack of skills to facilitate weight management effectively leads to failure to face this issue often both for themselves and also for their patients.

Aim

The main aim of this position paper is to explore dietary habits, obesity and university life for nurse undergraduates. 


\section{Method}

This critical review covers three distinct dimensions of student life as related to nursing studies, i.e.

- The eating and lifestyle behaviours of nursing students

- The transitional period and risk of gain weight

- Students' national origin and eating behaviors

Also, a critical summary overview with typical country examples of obesity prevalence amongst university student samples as shown in the literature was compiled (table 1). Yet, it should be noted that although there are a series of sound publications on this subject in Spanish this review is only dealing with sources in English.

\section{Findings}

Obesity is a major concern due to the rate at which it is increasing not only in the western world but in developing countries as well. University students, within the context of higher education, are provided with information regarding nutrition and healthy lifestyles are promoted via university life. Still, a multicenter study involving 22 countries and 15.700 university students found a high prevalence of overweight/obesity among university students (Peltzer et al., 2014). Some of the gender specific health risk practices that were identified could be incorporated into health promotion programs. As they pointed out, male students had a higher mean frequency of physical activity than females, and physical inactivity was related to obesity. Thus, universities need to address their obesogenic environment and promote healthy life styles.

The following table depicts prevalence rates of obesity amongst university students from some sample countries and continents which indicates a global concern. 
Theofanidis Dimitrios, Fountouki Antigoni

Table 1 prevalence rates of obesity

\begin{tabular}{|c|c|c|}
\hline Country & Student Obesity \% & reference \\
\hline \multicolumn{3}{|c|}{ Europe } \\
\hline Germany & $40 \%$ & Lehmann et al., 2014 \\
\hline Spain & $17 \%$ & Cutillas et al., 2013 \\
\hline \multicolumn{3}{|c|}{ Africa } \\
\hline Nigeria & $10 \%$ & Cutillas et al., 2013 \\
\hline South Africa & $50 \%$ & Van den Berg et al., 2012 \\
\hline \multicolumn{3}{|c|}{ Asia } \\
\hline Thailand & $31 \%$ & Banwell et al., 2009 \\
\hline Iran & $12.4 \%$ & Nojomi\&Najamabadi, 2006 \\
\hline \multicolumn{3}{|c|}{ South America } \\
\hline Colombia & $14.5 \%$ & Vargas et al., 2008 \\
\hline Mexico & $31.6 \%$ & Trujillo-Hernández, et al., 2010 \\
\hline
\end{tabular}

The eating and lifestyle behaviours of nursing students

Undoubtedly, university life is a big change in the lifestyle and habits of students, as a new way of life there is more freedom, independence, interpersonal relationships and experiences. Most students have exclusively the responsibility of their diet as they have to live alone, away from their family that used to take care of this part of their life; some students cook or eat out while some others decide to consume junk food (Deliens et al., 2014).

A study by Evagelou et al., (2014) on a sample of 435 Greek nursing students showed that unfortunately they tend to move away from their well renowned, healthy national traditional Mediterranean diet. In addition, the study indicated that a third of these nurses started smoking before the age of 17 . Thus, the authors suggest that health promotion programs should be encouraged early in the nursing curriculum in order for nursing graduates to establish associated learning and skills. This way, they would be aware, practice and also teach healthy diets and lifestyles.

80 Instituto de Investigación y Evaluación Educativas y Sociales / Universidad Pedagógica Nacional Francisco Morazán

Los artículos de la Revista Electrónica Paradigma del Instituto de Investigación y Evaluación Educativas y Sociales de la Universidad Pedagógica Nacional Francisco Morazán, se comparten bajo términos de la Licencia Creative Commons: Se permite que otros puedan descargar las obras y compartirlas con otras personas, siempre y cuando se reconozca su autoría, pero no se pueden cambiar de hinguna manera ni se pueden utilizar comercialmente. 
In another European country, a recent study on German nursing students illustrates explicitly the level of concern: almost $40 \%$ were either overweight or obese, close to $29 \%$ exercised less than once a week, 43\% smoked between 10 and 20 cigarettes a day and 73\% drank alcohol of which $20 \%$ did so in risky quantities (Lehmann et al., 2014). More worryingly in comparison to an earlier study in 2008 overweight, obesity and alcohol consumption had increased significantly.

Research from Spain, substantiates the fact that there should be better dietary and lifestyle habits amongst nursing students. Overall, there is an educational gap whereby student nurses should be encouraged to take regular physical exercise, practice healthy lifestyles and select optimum dietary choices (Irazusta et al., 2006).

Another study investigated nutritional knowledge and eating practices of 161 undergraduate nurse students in South Africa. The sample was shown to have an even higher prevalence of overweight and obesity $(50 \%)$ coupled with poor eating habits and inadequate knowledge of basic nutritional issues. Again, the authors questioned the students' future capability of being professional role models for a healthy society (van den Berg et al., 2012).

In these lines, a study on the association of eating disorders and body image disturbances in a sample of 97 nursing students, found a significant positive correlation between body mass index and body shape (Balhara et al., 2012). Despite its small sample, the study rings an alarm bell concerning distorted eating attitudes of female nursing students in India. In this context, one could speculate that dietary issues amongst student populations are of rising concern.

The eating behaviour that students eventually develop during their studies may accompany them for several years of adulthood and hence determine their health status; therefore the formation of a healthy eating and lifestyle behaviour is important.

Students made aware of the importance of this should be encouraged to set themselves standards of responsible care to maintain good health. The diet of students today is characterized by irregular meals, 
increased consumption of various snacks and alcohol. Several meals during the day are omitted and more often students avoided breakfast and lunch (Blichfeldt \& Gram, 2013).

Studies on students' eating behaviours showed that students studying away from home and living on their own engaged in more unhealthy eating habits in relation to students who stay with their parents (Kok, 2013). However, a study found that students, who come from big urban cities with both parents working full-time, eat more ready meals and junk food in comparison to students from smaller rural towns (Seguin et al., 2014). Other studies on student populations showed that some of the factors affecting eating behaviour, many of them were mentioned earlier, are taste, lack of time, self-control, price of products along with limited budget and the access to healthy foods (Deliens et al., 2014). All these studies highlight the fact that students change their eating behaviour for the worse.

On the other hand, an earlier study from Greece (Georgiou et al., 1977) suggested that graduates had more healthy habits and made more healthy choices regarding nutrition than nonstudents. This was confirmed by a more recent study, investigating the same variables, revealed that nonstudents had poorer dietary habits in comparison to students (Nelson, 2009). The researchers concluded that students engage healthy eating due to knowledge gained through studying. Furthermore, although researches show that students' eating behaviour is getting worse, some qualitative studies by conducting interviews and focus groups revealed that most students perceived their eating behaviours as satisfactory.

In addition, those who were aware of not having healthy habits and were not satisfied with their body and image, were not willing to do anything to change although they wanted to lose weight. All these results lead to the conclusion that while students know what they should be eating and what to avoid, follow an unhealthy eating pattern, as their eating habits are largely dependent on factors such as convenience, taste and the limited time. What is more, education and nutritional knowledge of students is not a factor that influences positively on their eating behaviour. 


\section{The transitional period and risk of gain weight}

In this transitional period, i.e. from 'protected' high school to 'independent' university life, freshman students face a new stage in life full of challenges, where they must make their own decisions, gain confidence, take responsibility for their daily life, manage their finances and organise a work schedule for their studies. It is a period that can define their whole life (Denovan \& Macaskill, 2013). This is the transitional stage where new students actually become independent and responsible for themselves. In this context, students should be aware of the impact between stress and uncontrollable eating habits which can lead to 'binge' eating and intractable obesity. Thus, a variety of strategies for coping with student-life stresses should be presented to them early in their studies. Hence, it has been suggested that students need easy access to counselling services in order to choose a personalized course of action and constructive options to deal with stress (Azza et al., 2014).

It has been reported in many studies that students do not have healthy eating patterns (Sepulveda et al., 2010; Perez-Cueto et al., 2009). In these lines, an study reported that only $8 \%$ of university students consumed the minimum recommended fruit and vegetable intake (Tavelli et al., 1998). Similar results were found in a study on university students where $69 \%$ of them were not consuming the recommended fruit and vegetable intake (Huang et al., 2003). However, a study conducted one year later showed that students, who lived independently, away from home, had a healthier eating behaviour than the students living with their parents (Beasley et al., 2004).

In Germany, a more recent study found that male university students had a balanced diet, where female students consumed high levels of fruits and vegetables and male students reported eating great amounts of fish, poultry and eggs (Sharma et al., 2010). Similarly, in Canada, a study conducted on first year male university students $(n=108)$ and found that they gained weight during the transition from high school to university, i.e. an average of $3.0 \mathrm{~kg}$ after the end of their last term (Pullman et al., 2009). A longitudinal observation study on freshmen students $(n=159)$ found that after the first semester almost 


\section{Theofanidis Dimitrios, Fountouki Antigoni}

one quarter had gained a significant amount of weight (Wengreen \& Moncur, 2009). This result shows that many but not all university students tend to gain weight during the transition to university.

\section{Students' national origin and eating behavior}

Every country in the world is characterized by great social diversity. The differences between countries may be due to matters of religion, culture and food habits and rituals. Dietary choices are multi-faceted, as they may include strongly embedded cultural elements but also incorporate technological advances as societies evolve. Thus, the eating behaviours of people are affected by many factors, such as climatic conditions, religious beliefs, scientific evidence, ideology, peer pressure, marketing and many more (Blas et al., 2011). Thus, food choice and eating are a form of social cohesion but also a means of communication and is connected with people's culture and lifestyle (Tirelli et al., 2013).

The number of students moving to a different country to study has been increasing in recent decades; the UK for example is one of the top choices for international education and the number of incoming students has been increasing steadily every year (Edwards et al., 2010). Yet, moving to a different country with a different culture to live and study could 'confuse' students and alter their eating behaviours. A study in the UK showed that moving to another country such as the UK whereby, for example, drinking and eating in pubs is quite common and could change dietary patterns and increase alcohol intake (Gordon-Larsen et al., 2003).

As reported by a recent study, Asian students, when abroad, decrease their consumption of meals per day and missed breakfast (Reed, 2014). Another study which was conducted on postgraduate students in the UK, found that international students were compelled to cook, having no other option, as they did not prefer eating local food (Brown, 2009). This helped the students feel more independent and self-efficient. 
On the other hand, some students in a different study in the UK appeared to be more adventurous with food choices, trying the local food and various international cuisines (Edwards et al., 2010). Also, the same study revealed that food had a social role as meal times with fellow students were when they connected the most and that sharing their food bonded groups better; however, all students reported that local food was not tasty and high in fat and sugar, making them feel concerned about their future health.

Irazusta et al., (2006) evaluated regular physical exercise and the dietary habits of a group of female nursing students $(n=46)$ and of a control group of female students from other disciplines $(n=58)$. Their results showed students were more sedentary in their first year. Still, diet analysis of the nursing students showed that their energetic intake was deficient and was low in carbohydrates and high in fat and protein. The study recommended that an adequate nutritional education element should be implemented early in the nursing curricula in order to encourage students to adopt healthier behaviors and to provide more effective nutritional counseling for their future patients.

In Turkey, a study on 310 nursing students found that about $30.0 \%$ had negative eating attitudes and there was a significant correlation between an increased depression level, decreased self-esteem and poor eating patterns (Celik et al., 2015).

\section{Discussion}

It is evident that it can be difficult to implement and maintain a healthy eating behaviour for any age group. Some of the reasons for this include lack of time and willpower, high cost, personal taste preferences or conscious decisions regarding personal diet, such as strong inclination for specific products.

Specifically, for students, it is even harder to start and follow a healthy eating behaviour during university. A relevant study on university students in the UK, conducted by revealed that only $18.6 \%(n=64)$ 
of the total sample $(n=345)$ reported to have healthy eating behaviours (Tanton et al., 2015). A possible reason for this low percentage might be insufficient knowledge which leads to improper choices. Yet, a study conducted few years ago on university students, found that $57 \%$ of male and $56 \%$ of female students were not familiar with healthy eating practices and had low nutritional awareness (Barzegari et al., 2011). According to the authors, some of the main causes were 'carelessness concerning nutrition', 'lack of information' and 'disinterest'. On the other hand, the same study revealed that students studying physical education had the highest nutritional knowledge (61\%).

A study assessing the body mass index (BMI) of 311 nursing students, examined the links between healthy dietary habits and BMI (Osaka et al., 1999). Results showed although $83 \%$ of their sample was within an acceptable BMI range, still, their choice of food was predominantly attributable to dieting for weight loss. Mintz \& Du Bois, (2002) concluded that the study of food and eating is important both as a vital life necessity and an important aspect of human behavior. According to Gearhardt et al., (2012) obesity is an international health issue affecting millions, primarily in the western world. Governments should focus more on promoting healthy behaviors via informative school policies, regulation of food marketing, explicit food labeling and the introduction of taxes on unhealthy foods. Along these lines, Bray, (2015) was early to emphasize the need for organized national and international meetings on obesity and the need for more scientific publications dealing with ways to fight obesity. Raubenheimer \& Simpson (2016) also are concerned with the continuing recent rise in obesity and associated cardiometabolic related diseases and suggest using their modeling approach from 'nutritional ecology' to provide a new direction in order to better understand and manage the problem.

Overall, it seems that nurses, amongst other healthcare professionals, encounter barriers to positive lifestyles and healthy eating just as their 'clientele' does. Nutritional knowledge may be difficult to grasp as there is so much misinformation readily available both online and elsewhere. Thus, in order to reeducate on basic nutritional principles, nursing students could learn more on simple nutritional principles 
such as consistency, portion size, and a nourishing variety that can help them make healthier food choices.

Therefore, by empowering student nurses with knowledge on how nutrition impacts metabolism and how healthy food choices can improve their personal health, this will hopefully help them to embrace positive eating and lifestyle habits. When student nurses adopt healthy habits, such as a varied diet, regular exercise and adequate sleep, they may deal with stress better and decrease the risk of weight destabilization.

\section{Conclusions}

Given the highly stressful conditions associated with their profession, it is important that nurses care for their own health in order to be able to help and care for their patients. Thus, good nutrition and healthy behaviors should be part of the daily routine of a nurse. In this context, healthy food choices may help maintain weight and improve energy levels.

The need for designing educational programs to prevent abnormal eating attitudes and coping with stress among nursing students is now urgent. In this context, reorganization of nursing curriculum to include early first year nutritional awareness and healthy lifestyle courses should be mandatory.

Thus, an adequate nutritional education should be early in the nursing educational program to encourage students to adopt healthier behaviors and to provide more effective preventive physical exercise and nutritional counseling for their future patients.

Nurses are on the front line in healthcare; as they adopt healthy living practices, the patients they care for may be more inclined to adopt healthy choices as well. The goal of any healthcare provider is to improve the lives of other people. Nurses can do that even more effectively by taking the lead and deciding that healthy living is as important to them as it is for the people they care for on a daily basis. 
Theofanidis Dimitrios, Fountouki Antigoni

\section{References}

Azza, M., Soad, A., \& Yousseria, E. (2014). Relationship between Stress and Eating Habits among Nursing Students. Assiut Med. J. Cairo Univ, 82(2), 47-55

Balhara, Y., Mathur, S., \& Kataria, D. (2012). Body Shape and Eating Attitudes among Female Nursing Students in India. East Asian Archives of Psychiatry, 22(2), 70-74

Banwell, C., Lim, L., Seubsman, S.A., Bain, C., Dixon, J., \& Sleigh, A. (2009). Body mass index and health-related behaviours in a national cohort of 87,134 Thai Open University students. J. Epidemiol Community Health, 63, 366-372

Barzegari, A., Ebrahimi, M., Azizi, M., \& Ranjbar, K. (2011). A study of Nutrition knowledge, attitudes and food habits of college students. World Applied Sciences Journal, 15(7), 1012-1017

Beasley, L., Hackett, A., \& Maxwell, S. (2004). The dietary and health behaviour of young people aged 18-25 years living independently or in the family home in Liverpool. International Journal of Consumer Studies, 28(4), 355-363

Blas, E., Sommerfeld, J., \& Sivasankara Kurup, A. (2011). Social determinants approaches to public health: from concept to practice. 1st ed. Geneva: World Health Organization

Blichfeldt, B. S., \& Gram, M. (2013). Lost in Transition? Student food consumption. Higher Education, 65(3), 277-289

Bray, G. A. (2015). Why Obesity? Annual Review of Nutrition 35, 1-31

Brown, L. (2009). The role of food in the adjustment journey of international students. In: H. M. Lindgreen A, ed. The New Cultures of Food: Marketing Opportunities from Ethnic, Religious and Cultural Diversity. (pp. 37-56). London: Gower Publishing Limited.

Instituto de Investigación y Evaluación Educativas y Sociales / Universidad Pedagógica Nacional Francisco Morazán

Los artículos de la Revista Electrónica Paradigma del Instituto de Investigación y Evaluación Educativas y Sociales de la Universidad Pedagógica Nacional Francisco Morazán, se comparten bajo términos de la Licencia Creative Commons: Se permite que otros puedan escargar las obras y compartirlas con otras personas, sienpre y cuando se reconozca su autoría, pero no se pueden cambiar de (1) -1 Pedagogica las obras y compartirlas con otras personas, 
Celik, S., Ugur, B., Aykurt, F., \& Bektas, M. (2015). Eating Attitudes and Related Factors in Turkish Nursing Students. Nursing and Midwifery Studies, 4(2), 1-8

Cutillas, A., Herrero, E., Eustaquio, A., Zamora, S., \& Pérez-Llamas, F. (2013). Prevalence of underweight, overweight and obesity, energy intake and dietary caloric profile in university students from the region of Murcia (Spain). Nutr Hosp. 28(3), 683-689

Deliens, T., Clarys, P., De Bourdeaudhuij, I., \& Deforche, B., (2014). Determinants of eating behaviour in university students: a qualitative study using focus group discussions. BMC Public Health, $14(1), 53-54$

Denovan, A., \& Macaskill, A. (2013). An interpretative phenomenological analysis of stress and. British Educational Research Journal, 39(6), 1002-1024

Edwards, J.S., Hartwell, H.L., \& Brown, L. (2010). Changes in food neophobia and dietary habits of international students. Journal of Human Nutrition and Dietetics, 23(3), 301-311

Evagelou, E; Polikandrioti, M; Koutelekos, I., Dousis, E., \& Kyritsi, E. (2014). Health Science Journal, 8(4), 452-468

Gearhardt, A.G., Bragg, M.A., Pearl, R.L., Schvey, N.A., Roberto, C.A., \& Brownell K.D. (2012). Obesity and Public Policy. Annual Review of Clinical Psychology 8, 405-430

Georgiou, C.C., Betts, N.M., \& Hoerr, S.L. (1997). Among Young Adults, College Students and Graduates Practiced more Healthful Habits and made more Healthful Food Choices than did Nonstudents. Journal of the American Dietetic Association, 97(7), 754-759

Gordon-Larsen, P., Harris, K., Ward, D., \& Popkin, B. (2003). Acculturation and overweight-related behaviors among Hispanic 
Theofanidis Dimitrios, Fountouki Antigoni

immigrants to the US: the National Longitudinal Study of Adolescent Health. Social Science E Medicine, 57, 2023-2034

Huang, T.T., Harris, K.J., Lee, R.E., \& Naziret, N. (2003). Assessing overweight, obesity, diet, and physical activity in college students. Journal of American College Health, 52(2), 83-86

Irazusta, A., Gil S., Ruiz F., \& Gil, J. (2006). Exercise, Physical Fitness, and Dietary Habits of First-Year Female Nursing Students. Biological Research for Nursing, 7(3), 175-186

Ismawati, S., Zainalabidin, M., \& Golnaz, R. (2014). Healthy Eating: The Preventive Factors among Malaysians. Journal of Economics, Business and Management, 2(4), 257-261

Keyworth, C., Peters S., Chisholm, A., \& Hart, J. (2013). Nursing students' perceptions of obesity and behaviour change: implications for undergraduate nurse education. Nurse Educ Today, 33(5), 481-485

Knutson, K. (2012). Does inadequate sleep play a role in vulnerability to obesity? American Journal of Human Biology, 24(3), 361-371. doi: 10.1002/ajhb.22219

Kok, C. M. (2013). Exploring Familial Themes in Malaysian Students' Eating Behaviors. Journal of Human Sciences and Extension, 1(1), 125-142

Kolleck, B. (2004). Smoking among nursing students. Pflege, 17(2), 98-104

Lehmann, F., von Lindeman, K., Klewer, J., \& Kugler, J. (2014). BMI, physical inactivity, cigarette and alcohol consumption in female nursing students: a 5-year comparison. BMC Medical Education, $14,82-89$

Mintz, S.W., \& Du Bois, C.M. (2002). The Anthropology of Food and Eating. Annual Review of Anthropology 31, 99-119 
Nelson, M.C; Larson, N.I., Barr-Anderson, D., Neumark-Sztainer, D., \& Story, M. (2009). Disparities in Dietary Intake, Meal Patterning, and Home Food Environments Among Young Adult Nonstudents and 2- and 4-Year College Students. American Journal of Public Health, 99(7), 1216-1219

Nojomi, M., \& Najamabadi, S. (2006). Obesity among university students, Teheran, Iran. Asia Pac. J. Clin. Nutr. 15, 516-520

Osaka, R., Nanakorn, S., Sanseeha, L., Nagahiro, C., \& Kodama, N. (1999). Healthy dietary habits, body mass index, and predictors among nursing students, northeast Thailand. The Southeast Asian Journal of Tropical Medicine and Public Health, 30(1), 115-121

Peltzer, K., Pengpid, S., Samuels, A., Özcan N., Mantilla, C., Rahamefy, O., Wong, M., \& Gasparishvili, A. (2014). Prevalence of Overweight/Obesity and its Associated Factors among University Students from 22 Countries. Int J Environ Res Public Health. 11(7), 7425-7441

Perez-Cueto, F., Verbeke, W., Lachat, C., \& Remaut-De Winter, A.M. (2009). Changes in dietary habits following temporal migration. The case of international students in Belgium. Appetite, 52(1), 83-88

Pullman, A.W; Masters, R.C., Zalot, L.C., Carde, L.E., Saraiva, M.M., Dam, Y.Y., Randall, Simpson J.A., \& Duncan, A.M. (2009). Effect of the transition from high school to university on anthropometric and lifestyle variables in males. Applied Physiology, Nutrition and Metabolism, 34(2), 162-171

Purcell, C., Moyle, W., \& Evans, K. (2006). An exploration of modifiable health associated risk factors within a cohort of undergraduate nursing students. Contemp Nurse. 23(1), 100-110

Raubenheimer, D., \& Simpson, S. (2016). Nutritional Ecology and Human Health. Annual Review of Nutrition 36:603:626 
Theofanidis Dimitrios, Fountouki Antigoni

Reed, D. (2014). Healthy Eating for Healthy Nurses: Nutrition Basics to Promote Health for Nurses and Patients. The Online Journal of Issues in Nursing, 19(3), 14-20

Seguin, R., Connor, L., Nelson, M., LaCroix, A., \& Eldridge, G. (2014). Understanding Barriers and Facilitators to Healthy Eating and Active Living in Rural Communities. Journal of Nutrition and Metabolism, 14, 1-8. doi: 10.1155/2014/146502

Sepulveda, A., Carrobles, J.A., \& Gandarillas, A.M. (2010). Associated Factors of Unhealthy Eating Patterns among Spanish University Students by Gender. The Spanish Journal of Psychology, 13(1),364375

Sharma, B., Harker, M., Harker, D., \& Reinhard, K. (2010). Youth transition to university in Germany and Australia: an empirical investigation of healthy eating behaviour. Journal of Youth Studies, 13(3), 353-367

Tanton, J., Dodd, L.J., Woodfield, L., \& Mabhala, M. (2015). Eating Behaviours of British University Students:A Cluster Analysis on a Neglected Issue. Advances in Preventive Medicine, 15, 1-8. doi:10.1155/2015/639239

Tavelli, S., Beerman, K., Shultz, J. \& Heiss, C. (1998). Sources of error in nutritional adequacy of the food guide pyramid. Journal of American College Health, 47, 77-82

Tirelli, C., Martínez-Ruiz, M.P., \& Gómez-Ladrón-De-Guevara, R. (2013). Major influences on buying decision processes by international university students. Differences by continent of origin. Appetite, 71, 104-112

Trujillo-Hernández, B., Vásquez, C., Almanza-Silva, J.R., JaramilloVirgen, M.E., Mellin-Landa, T.E., Valle-Figueroa, O.B., PérezAyala, R., Millán-Guerrero, R.O., Prieto-Díaz-Chávez, E., \& Newton-Sánchez, O. (2010). The frequency of risk factors 
associated with obesity and being overweight in university students from Colima, Mexico. Rev. Salud Pública, 12, 197-207

Van den Berg, V., Okeyo, A., Dannhauser, A., \& Nel, M. (2012). Body weight, eating practices and nutritional knowledge amongst university nursing students, Eastern Cape, South Africa. African Journal of Primary Health Care E Family Medicine, 4(1), 323-331

Vandelanotte, C., Duncan, M.J., Hanley, C., \& Mummery, W.K. (2011). Identifying population subgroups at risk for underestimating weight health risks and overestimating physical activity health benefits. Journal of Health Psychology, 16(5), 760769

Vargas, M., Becerra, F., \& Prieto, E. (2008). Anthropometric evaluation of university students in Bogotá, Colombia. Rev. Salud Pública, 10, 433-442

Wengreen, H.J., \& Moncur, C. (2009). Change in diet, physical activity, and body weight among young-adults during the transition from high school to college. Nutrition Journal, 8,32-37 